Original Research Paper

\title{
Evaluating Rainwater Harvesting System for School Buildings
}

\author{
Manoj K. Jha and Nishant Shah \\ Department of Civil, Architectural and Environmental Engineering, \\ North Carolina A\&T State University, Greensboro, North Carolina, USA
}

Article history

Received: 28-02-2015

Revised: $15-03-2015$

Accepted: 6-07-2015

Corresponding Author:

Manoj K. Jha

Department of Civil,

Architectural and

Environmental Engineering,

North Carolina A\&T State

University, Greensboro, North

Carolina, USA

Email:mkjha@ncat.edu

\begin{abstract}
Freshwater is becoming limited as our climate and weather pattern changes. In this study, a rainwater harvesting system was evaluated for collecting and utilizing rainwater for uses in non-potable purposes. Water-Balance was carried out for two design scenarios: Single tank and double tank, for irrigation in all main fields $\left(202,724 \mathrm{ft}^{2}\right)$. The irrigation demand for the entire field was estimated to be about 1.08 million gallons on average after analyzing 14 years of data (2000-13). Installing a single tank of 210,000 gallon capacity was found to reduce the demand by $23 \%$, whereas double tank installation was found to reduce the demand by about $10 \%$ on an annual basis. For these demand, irrigation needs has to depend on other sources such as city water supply or school's retention pond. The cost-benefit analysis revealed that the system will have estimated initial cost of $\$ 85,000$ (single tank installation). The corresponding annualized cost of ownership is $\$ 5,215$ while projected savings on annual water bills is $\$ 6,079$. The system could be paid off early, resulting in savings of about $\$ 45,000$ for the life of the system. The system was found to benefit financially while contributing to the environment by conserving the freshwater from non-potable use and reducing hydrologic footprint by harvesting the stormwater runoff.
\end{abstract}

Keywords: Rainwater Harvesting, Cost-Benefit Analysis, Urban Stormwater

\section{Introduction}

NetZero is a challenge that may seem farfetched, but it is a concept that may become reality in near future. As our population along with our needs for energy and water increases, there is a growing realization that our environment will not be able to sustain our needs for much longer at the current rate. NetZero or living building challenge is a challenge to design a system to be fitted on buildings that allow the buildings to be independent of the local power, water and sewage systems. In other terms, it means designing or modifying an existing system in a residential or commercial building in such a way that it is "off the grid." It focuses on recycling, reusing and harvesting renewable resources with minimalist impact on the environment. NetZero system starts with conservation, recycling and reusing.

In this research, we are focusing on NetZero water challenge. NetZero water is probably the least researched area in NetZero challenge. It is also one of the most challenging aspects of NetZero challenge. With changing climate and increased frequencies of draughts, NetZero water concept has potential to alleviate the scarcity of freshwater. It can help build a better sustainable future while reducing environmental impacts such as controlling wastage of freshwater in non-potable use and reducing flood and bank erosion risks due to excessive stormwater in the stream (Sisolak and Spataro, 2011). NetZero water challenge is a broad and complex topic.

There are many methods to achieve NetZero water. In this research, we focus and elaborate on the rainwater harvesting technique (Khastagir and Jayarurya, 2010). Millions of gallons of potentially usable rainwater are lost to streams every day. This water could be harvested, collected and stored to be used later for non-potable purposes such as irrigation, toilet flushing, cooling/heating applications, car washing, etc. This will reduce the use of freshwater for these applications and will ease the load on city to treat and process the water.

There are several successful examples of utilizing rainwater harvesting models. Herrmann and Schmida (2000) demonstrated the potential of potable water saving to range from $30 \%$ to $60 \%$, depending on the non-potable water demand and roof area. Fettes et al. (2009) designed a system that was cost effective with payback period of 18 months; however, their research 
had several over estimation and assumption of snowmelt collected. Coombes et al. (2000) in their analysis of 27 residential units identified about $60 \%$ saving in potable water use. Similarly, Ghisi et al. (2006) in their analysis of 62 cities in Southern Brazil showed potential water saving of about $69 \%$ on average. Performance of rainwater harvesting systems in the southeastern United States was evaluated by Jones and Hunt (2010). They studies about 2081 rain barrels and larger cisterns across Southeast and concluded that the rainwater harvesting systems were underutilized due to poor estimation of water usage and public perception of the system.

The rainwater harvesting system has been proven to conserve freshwater resource. However, it depends on many factors including amount of water that can be collected, non-potable use of water, economic feasibility and most importantly public perception of the system and its benefit in water conservation and ecosystem. The current study attempts to analyze the feasibility of a rainwater harvesting system in school buildings. The objectives are to (1) determine the optimal size of the cistern that will collect and supply the water demand for irrigating sports fields and (2) cost-benefit analysis of installing the cistern in the case of a high-school building network located in Greensboro, North Carolina. Schools usually have collection of large buildings which can potentially collect large quantity of rainwater, which can be used for many non-potable usages, mainly irrigation of the lawn and fields.

\section{Materials and Methods}

\section{Rainwater Harvesting (Supply)}

Western Guilford High School (WGHS) located in west side of the City of Greensboro, North Carolina was selected for the design and cost-benefit analysis of a rainwater harvesting system. The school uses city water, year around for all of its applications. Figure 1 shows school buildings and areal estimates of the rooftop area that will be used for collecting rainwater. The surface area of each of the rooftop was estimated using Bing's Map area feature from the bird's eye view (http://www.bing.com/maps/). It should be noted that the area determined using this method is only the closest possible estimates and that actual area may be bigger or smaller. The total area estimated was $150,823 \mathrm{ft}^{2}$ (West wing + Main + East wing + Front).

To determine the amount of rainwater that can be collected through school's rooftops, we first acquired the historical rainfall observation data in the study area. The daily rainfall data was collected from the USGS website (http://nc.water.usgs.gov/) for 14 years (2000-13). Data was aggregated into weekly rainfall amount to calculate the total water produced in a week time by rooftop [Volume of rainwater harvested $=$ Rainfall depth $*$ Roof area].

\section{Need for Irrigation (Demand)}

Figure 2 shows the Bing's Map area feature's estimated area of the sports fields of WGHS which would to be irrigated using the harvested rainwater from rooftop. There are many sports fields and practice fields which will require significant amount of irrigation. Personal communication with school staff advised that the school does not irrigate all of its fields. According to Coach Kausey, only the main football, soccer and baseball fields have sprinkler systems and are irrigated regularly. $\mathrm{He}$ is in charge of irrigation which normally takes place from late May to September every year. Due to lack of moisture sensors, staff is in charge of controlling the time the sprinklers stay on. The length of time is dependent upon the rainfall that may have occurred over the season. With this information, we estimated the total irrigation area of the main sport fields (football, soccer, baseball) to be $202,724 \mathrm{ft}^{2}$.

Irrigation demand was calculated on a weekly basis for water balance for comparing against the weekly water volume stored from rooftop. In the city of Greensboro, school doesn't start irrigation until late May and it ends in September when it starts getting cooler. According to the North Carolina Department of Environment and Natural Resources, about 1" of water per sq. ft. per week is required to maintain lawns in city's dominant clay soil types (NC DENR, 2015).

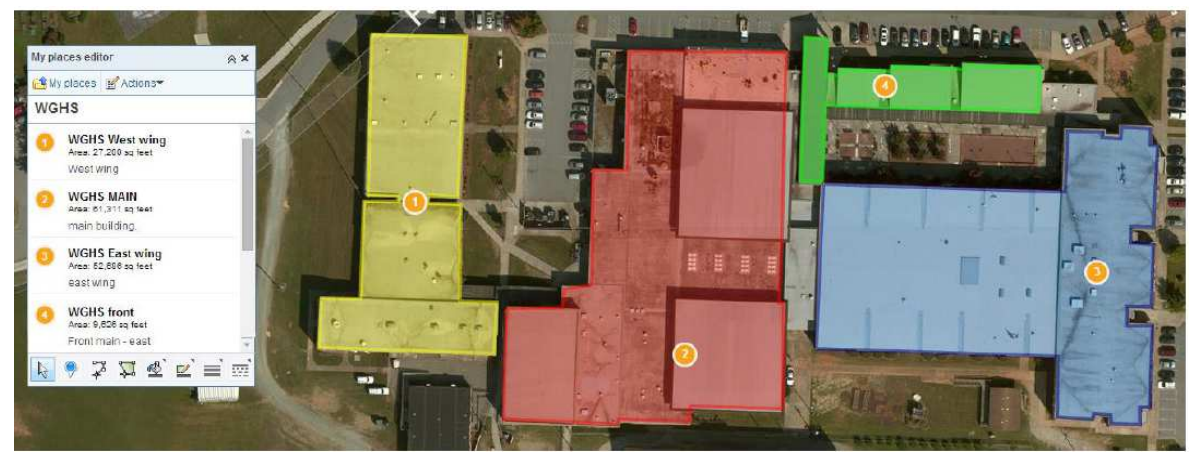

Fig. 1. WGHS's rooftops to be used in surface area calculation for harvesting the rainwater 


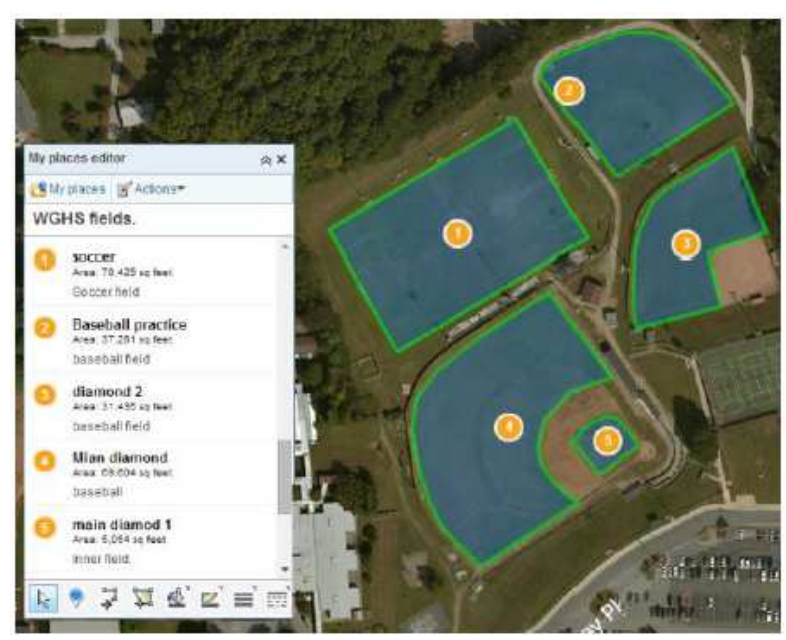

Fig. 2. Areal estimate of sports fields at WGHS for irrigation demand calculation

However, an inch of water may not be required for all of the weeks due to rainfall for that week. To account for that, rainfall for that week was deducted from an inch if it is below an inch. If the rainfall amount is more than an inch for a week, then no irrigation is required for that week. This method is efficient and can be made possible by use of the moisture sensors in conjunction with sprinkler systems:

Irrigation demand $=$ Irrigation area * (Irrigation amount I - rainfall $\mathrm{P}$ adjustment)

Rainfall adjustment:

$\mathrm{I}=1$ in. if $\mathrm{P}=0$ for the week

$\mathrm{I}=0$ if $\mathrm{P}>1$ in. for the week

$\mathrm{I}=(1$ in. $-\mathrm{P})$, if $\mathrm{P}<1$ in. for the week

\section{Results and Discussion}

\section{Design of the Cistern: Water Balance Analysis}

Weekly supply of water (rainfall volume stored from rooftop) and weekly demand of irrigation (of school's sports fields) were compared to compute the size of the storage needed. A weekly mass balance was conducted and the cumulative deficit amount was calculated for each of the deficit period. A deficit (need of irrigation) starts any week and ends when irrigation is completely met by rainfall. A new deficit period starts again when there is need of water for irrigation. The analysis was conducted for the entire 14 years within which many deficit periods were detected. The highest cumulative deficit amount was chosen as the minimum size of storage needed to fulfill the irrigation demand during all deficit periods.

From our data analysis, it was noted that the irrigation demand is significantly higher compared to the potential storage. Rainwater collected on rooftop area was not able to compensate all of the irrigation needs throughout the year. Due to this situation, it was important that we first select the size of the tank which is largest available while being cost friendly and then determine how much of demand can be met; the rest then can be dependent on city's water supply or other possible sources. For this change in the method of calculation, we modified our water balance model using approaches developed by the Maryland Department of Environment (MDE) for stormwater design guidance with reference to the rainwater harvesting (MDE, 2000). According to this method, an initial assumption for the size of cistern is required to determine the best size possible.

The largest tank available in the market, while being cost friendly with low maintenance option, is pillow tank which is of 210,000 gallon capacity (WST, 2015). The dimension of the tank is $75^{\prime} \times 73^{\prime} \times 6$ '. The size of the tank makes it hard to store it anywhere else but on the ground. Storing on the roof would eliminate the need for pump and increase the water pressure, but that is not possible. Placing it on the roof would reduce the rainwater collection area significantly. Also, these tanks need to be flat on the ground and preferably in shade for longevity. Ground cover and enclosure can also increase its life span.

We used two scenarios, one with single tank and other with two tanks to determine the maximum irrigation that can be served. In the water balance calculation, the cumulative storage provided in a storage tank through the week minus the demand of that week yields the total storage at the end of the week. When the water demand is low and rainfall is high week after week, the water will accumulate over 210,000 gallons and overflow out of the tank. Conversely, when the demand is and rainfall is low, the water will deplete to 0 gallons and would use city water or other source. Since the tank would hold no more than 210,000 gallons of rainwater, the cumulative storage in the tank was calculated as shown below:

If cumulative storage $<0$, end of the week balance $=0$

If cumulative storage $<210,000$, end of the week balance $=$ Cumulative storage

If cumulative storage $>210,000$, end of the week balance $=210,000$ gallons

Water-Balance was carried out for two design scenarios: single tank and double tank, for all irrigation in all main fields $\left(202,724 \mathrm{ft}^{2}\right)$. Table 1 shows all the data analysis along with cost analysis (next sub-section). Weekly irrigation demand and rainwater harvested were aggregated on an annual basis. The irrigation demand for the entire field was determined to be over 15 million gallons over the span of 14 years. On average, installing a single tank of 210,000 gallon capacity was found to reduce the demand by $23 \%$, whereas double tank installation was found to reduce the demand by about $10 \%$. For these unfulfilled demands, irrigation needs has to depend on other sources of water such as city water supply or school's retention pond. 
Table 1. Irrigation demand and cost analysis of the single and double tank system for all sports field (area $=202,724 \mathrm{ft}^{2}$ )

\begin{tabular}{|c|c|c|c|c|c|c|c|c|}
\hline \multirow[b]{2}{*}{ Year } & \multicolumn{2}{|c|}{ Without Tank(s) } & \multicolumn{3}{|c|}{ Single Tank } & \multicolumn{3}{|c|}{ Double Tank } \\
\hline & $\begin{array}{r}\text { Irrigation } \\
\text { (gallons) }\end{array}$ & $\begin{array}{l}\text { Cost } \\
(\$)\end{array}$ & $\begin{array}{r}\text { Irrigation } \\
\text { (gallons) }\end{array}$ & $\begin{array}{l}\text { Cost } \\
(\$)\end{array}$ & $\begin{array}{l}\$ \\
\text { Saved }\end{array}$ & $\begin{array}{r}\text { Irrigation } \\
\text { (gallons) }\end{array}$ & $\begin{array}{l}\text { Cost } \\
(\$)\end{array}$ & $\begin{array}{l}\$ \\
\text { Saved }\end{array}$ \\
\hline 2000 & 813788 & 5973 & 0 & 0 & 5973 & 0 & 0 & 5973 \\
\hline 2001 & 969217 & 7114 & 91257 & 670 & 6444 & 0 & 0 & 7114 \\
\hline 2002 & 1405175 & 10313 & 612250 & 4494 & 5820 & 370399 & 2719 & 7595 \\
\hline 2003 & 863070 & 6335 & 295459 & 2169 & 4166 & 105459 & 774 & 5561 \\
\hline 2004 & 902243 & 6622 & 0 & 0 & 6622 & 0 & 0 & 6622 \\
\hline 2005 & 1227001 & 9006 & 407895 & 2994 & 6012 & 217895 & 1599 & 7406 \\
\hline 2006 & 831479 & 6103 & 99322 & 729 & 5374 & 0 & 0 & 6103 \\
\hline 2007 & 1750150 & 12845 & 785226 & 5763 & 7082 & 595226 & 4369 & 8477 \\
\hline 2008 & 964162 & 7077 & 220683 & 1620 & 5457 & 0 & 0 & 7077 \\
\hline 2009 & 935098 & 6863 & 88304 & 648 & 6215 & 0 & 0 & 6863 \\
\hline 2010 & 1185300 & 8700 & 512330 & 3760 & 4939 & 201720 & 1481 & 7219 \\
\hline 2011 & 1156236 & 8486 & 257397 & 1889 & 6597 & 8492 & 62 & 8424 \\
\hline 2012 & 1148654 & 8431 & 11921 & 87 & 8343 & 0 & 0 & 8431 \\
\hline 2013 & 946471 & 6947 & 121360 & 891 & 6056 & 0 & 0 & 6947 \\
\hline Total & $15,098,046$ & 110,813 & $3,503,403$ & 25,713 & 85,100 & $1,499,190$ & 11,003 & 99,810 \\
\hline Ave. & $1,078,432$ & 7,915 & 250,243 & 1,837 & 6,079 & 107,085 & 786 & 7,129 \\
\hline
\end{tabular}

Note: Cost was calculated based on $\$ 5.49$ per 748 gallon of water (1 UNIT)

\section{Cost-Benefit Analysis}

School's water bill was collected and analyzed to identify the cost of irrigation and how much saving could be achieved with the use of the cistern. The city charges $\$ 2.45$ per UNIT for water and $\$ 3.04$ per UNIT for sewage. The sewage UNITS are based on the UNITs of water. So, the total per UNIT cost of water including water supply and sewage was established at $\$ 5.49$. According to city, UNIT is defined as 748 gallons or $100 \mathrm{ft}^{3}$ of water. Amount of water saved due to water tanks were calculated by multiplying the saved irrigation water with the unit rate of $\$ 5.49$ for each 748 gallons. Table 1 shows all calculation on an annual basis for 14 years. On average, annual irrigation cost was found to be $\$ 7,915$. Single tank installation reduced the cost by $77 \%$. Similarly, double tank installation reduced the cost by $90 \%$.

To determine the true benefits of the system, we must also take in consideration the amount the city will have to spend to install the system. Equipment cost, labor cost and maintenance cost was taken into consideration to calculate the annualized cost of the installation for life of the system. Annualized cost was calculated using:

$$
A=P\left[\frac{i(1+i)^{n}}{(1+i)^{n}-1}\right]
$$

where, $\mathrm{A}$ is the annualized cost, $\mathrm{P}$ is principle cost, $\mathrm{i}$ is interest rate and $n$ is life-span of the system. Initial cost is converted into annualized cost and then annual maintenance cost is added to determine the total annualized cost of the installation. While there is no solid evidence about how long the system will last, according to the Labaronne-Citaf website (http://www.labaronne-citaf.com/-Self-supporting- closed-flexible-.html), they have tanks that have been in operation for more than 35 years. To be safe, we have assumed the life of the system to be 30 years. Also, the interest rate was assumed to be $4.5 \%$, a current market rate for a fixed 30 years. Total annualized cost for a single tank came out to be $\$ 5,215$, which included purchase cost $(\$ 74,444)$, gutter and fitting $(\$ 5,000)$, enclosure and groundcover $(\$ 2,000)$, moisture sensors (\$500) and pump $(3,000)$. Similarly, annualized cost for the double tank came out to be $\$ 9,785$.

From the cost data of installation and benefit of saving city's water, it is observed that the cost per year for owning "two-tank system" is higher than the amount saved on water bills per year, so this will not be a wise decision. The system with combination of single tank with irrigation area of all the main sports fields is found to be a feasible option. The average savings per year after paying of the annualized cost for the system is estimated to be $\$ 864 /$ year ( $=\$ 6,079-\$ 5,215$ ). However, if this extra money were to go to paying of the system early, the savings can be even greater for the life of the system. Using an Early Payoff Calculator, we were able to determine the schedule of loan and amount saved on interest. By paying of the loan in seven year and eleven months, the system can save school a total of $\$ 6,079$ per year. This amounts to approximate saving of $\$ 48,632$ after paying off the system. This proves that significant amount of financial saving is possible with this system.

Analysis was further extended to leverage the current retention pond of the school for drawing water during the deficit time of the rainwater harvesting system. The area of the pond was determined using the Bing's Map area feature. We estimated the average depth of the pond to be six feet based on the data provided by the Environmental Protection Agency that the retention pond 
in U.S. are ranging from three to nine feet deep (USEPA, 1999). This allowed us to determine the maximum capacity of the pond. Further water balance analysis revealed that the pond was able to supply water for all of the irrigation needs without depleting is supply. If the school were to pull its irrigation water from the pond, the school will not have to pay any cost due to irrigation. Using the data from last 14 years, we were able to find that the school would have saved close to $\$ 10,000$ per year in water usage due to irrigation.

\section{Concluding Remarks and Future Research}

From our analysis, we can see that the rainwater harvesting technique would be most beneficial to a building that has large surface area and greater irrigation demand. Lowered water consumption along with lower hydrological footprint will contribute to sustainability. It will reduce water usage and energy consumption for the school. It will decrease stormwater runoff and increase awareness of sustainability for students. The storage of rainwater gives the school extra options. It can be used for emergencies like fire as well. It can be used to start a vegetable garden around the school buildings to promote healthy living. Water consumption can be lowered further, if the system can be used in winter months to provide for black and grey water. During winter months, irrigation demand is minimal if any, so the water is stored and not used. The stored water can compensate for grey and black water, which in turn can lead to even more financial savings.

The city will benefit from water conservation and reduced hydrological footprint. The reduced runoff and usage will decrease the burden on city to process and treat the water during peak times. This will lead to lower resources and energy consumption. Other benefits are increased productivity, financial savings and decreased carbon footprint. This type of system would have a greater demand in developing countries but, developed nations such as U.S. can still benefit from them. Due to changes in weather pattern and hotter climates, southern and western states are experiencing droughts. These types of systems can really be beneficial where rainfall is low and water is more expansive.

While the financial benefits for this system may vary by location, the environmental benefits will always be there. The system is beneficial for the local ecosystem. It can reduce floods and prevent soil erosion. The rainwater harvesting system for use in irrigation can increase groundwater levels instead of depleting them. The system mimics the natural cycle of water by slowly going through the process of infiltrating the groundwater.

For location with high irrigation demand, the cost of storage could be expansive. A possible idea that requires research is using the retention pond to store rainwater. This pond may be used to irrigate the area with the pump. Further research also needs to be done on making the collected water usable for grey and black water applications. What would be the benefits and disadvantages of these applications? For drought prone areas, research on making the collected water usable for potable purpose, could be lifesaving. That would require research on filtration and water quality.

\section{Acknowledgment}

This work was financially supported by the Center of Energy Research and Technology (CERT) at North Carolina A\&T State University, Greensboro, North Carolina, USA.

\section{Author's Contributions}

Manoj K. Jha: Contributed in the developing the research method; designing the experiments; and writing/editing the manuscript.

Nishant Shah: Contributed in executing the research method, run, result analysis and writing the report.

\section{Ethics}

This article is original and contains unpublished material. The corresponding author confirms that all of the other authors have read and approved the manuscript and no ethical issues involved.

\section{References}

Coombes, P.J., J.R. Argue and G. Kuczera, 2000. Figtree Place: A case study in water sensitive urban development. Urban Water, 4: 335-343. DOI: 10.1016/S1462-0758(00)00027-3

Fettes, G., M. Garcia and D. Janssen, 2009. Rainwater harvesting design. College of Engineering Research, University of Guelph.

Ghisi, E., A. Montibeller and R. Schmidt, 2006. Potential for potable water savings by using rainwater: An analysis over 62 cities in southern Brazil. Building Environ., 41: 204-210. DOI: 10.1016/j.buildenv.2005.01.014

Herrmann, T. and U. Schmida, 2000. Rainwater utilization in Germany: Efficiency, dimensioning, hydraulic and environmental aspects. Urban Water, 1: 307-316. DOI: 10.1016/S1462-0758(00)00024-8

Jones, M.P. and W.F. Hung, 2010. Performance of rainwater harvesting systems in the southeastern United States. Resources, Conservation Recycling, 54: 623-629. DOI: 10.1016/j.resconrec.2009.11.002

Khastagir, A. and N. Jayasuriya, 2010. Optimal sizing of rain water tanks for domestic water conservation. J. Hydrol., 381: 181-188.

DOI: 10.1016/j.jhydrol.2009.11.040 
MDE, 2000. Maryland stormwater design manual, volumes I and II. Maryland the Department of the Environment. Sisolak, J. and K. Spataro, 2011. Toward net zero water: Best management practices for decentralized sourcing and treatment. Cascadia Green Building Council.
USEPA, 1999. Stormwater technology fact sheet: Wet detention ponds. EPA 832-F-99-048. Washington, D.C.

WST, 2015. Water storage portable tanks: Pillow tanks. 